\title{
Erratum to: Early postoperative mortality after simultaneous or staged bilateral primary total hip arthroplasty: an observational register study from the Swedish Hip Arthroplasty Register
}

\author{
Anne Garland ${ }^{1,2,4^{*}}$, Ola Rolfson ${ }^{2,3,5}$, Göran Garellick ${ }^{2,3}$, Johan Kärrholm²,3 and Nils P. Hailer ${ }^{2,4}$
}

\section{Erratum:}

The original version of this article unfortunately contained a mistake in the section entitled "Revision surgery". The corrected text is given below:

\section{Corrected text:}

(Page 5: Results - Revision surgery)

Revision surgery of either hip after the second THA surgery was slightly more common in simultaneously operated patients compared to the patients operated with a staged procedure (Simultaneous surgeries 240 [7.1\%], surgeries within6 months n 495 [5.1\%], surgeries between 7 and 12 months $n 828$ [5.3\%] and second surgery after $>12$ months n 3,573 [6.4\%]).

The unadjusted risk of revision for the simultaneously operated patients compared to the patients operated with staged procedure was [HR 1.6, CI 1.3-1.9] (surgeries within 6 months [HR 1.2, CI 1.1-1.4], surgeries between 7 and 12 months [HR 1.1, CI 1.0-1.3] with second surgery after $>12$ months as the reference group). When adjusting for sex, age, diagnosis and type of prosthesis fixation this difference in the risk estimates disappeared (simultaneous bilateral [HR 1.1, CI 0.9-1.4], surgeries within 6 months [HR 1.1, CI 1.0-1.3], surgeries between 7 and 12 months [HR 1.1, CI 1.0-1.2] with second surgery after $>12$ months as the reference group).

\section{Author details}

'Department of Orthopaedics, Visby Hospital, Visby, Sweden. ${ }^{2}$ Swedish Hip Arthroplasty Register, Gothenburg, Sweden. ${ }^{3}$ Department of Orthopaedics, Institute of Clinical Sciences, The Sahlgrenska Academy, University of Gothenburg, Gothenburg, Sweden. ${ }^{4}$ Department of Orthopaedics, Institute of Surgical Sciences, Uppsala University Hospital, Uppsala, Sweden. ${ }^{5}$ Harris Orthopaedic Laboratory, Massachusetts General Hospital, Harvard Medical School, Boston, USA.

Received: 11 September 2015 Accepted: 11 September 2015 Published online: 28 September 2015

\section{Reference}

1. Garland et al. BMC Musculoskelet Disord. 2015;16:77. doi:10.1186/s12891-015-0535-0.

\footnotetext{
* Correspondence: anne.garland@gotland.se

1 Department of Orthopaedics, Visby Hospital, Visby, Sweden

${ }^{2}$ Swedish Hip Arthroplasty Register, Gothenburg, Sweden

Full list of author information is available at the end of the article
}

\section{Submit your next manuscript to BioMed Central and take full advantage of: \\ - Convenient online submission \\ - Thorough peer review \\ - No space constraints or color figure charges \\ - Immediate publication on acceptance \\ - Inclusion in PubMed, CAS, Scopus and Google Scholar \\ - Research which is freely available for redistribution}

Submit your manuscript at

www.biomedcentral.com/submit

() Biomed Central 